\title{
Perceptions and misperceptions of overdetection of breast cancer
}

\author{
Jesse Jansen $^{1,2}$, Nehmat Houssami ${ }^{1}$ \\ ${ }^{1}$ Wiser Healthcare, Sydney School of Public Health, ${ }^{2}$ Sydney Health Literacy Lab, Sydney School of Public Health, Faculty of Medicine and Health, \\ University of Sydney, Sydney, NSW, Australia \\ Correspondence to: Nehmat Houssami. Sydney School of Public Health (A27), Faculty of Medicine and Health, University of Sydney, Sydney, NSW \\ 2006, Australia. Email: nehmat.houssami@sydney.edu.au. \\ Comment on: Pappadis MR, Volk RJ, Krishnan S, et al. Perceptions of overdetection of breast cancer among women 70 years of age and older in the \\ USA: a mixed-methods analysis. BMJ Open 2018;8:e022138.
}

Submitted Aug 29, 2018. Accepted for publication Sep 07, 2018.

doi: $10.21037 /$ tcr.2018.09.08

View this article at: http://dx.doi.org/10.21037/tcr.2018.09.08

\section{An overview of overdetection}

In the rapidly progressive world of cancer research and discovery, concerns about overdetection, or overdiagnosis, whether relating to breast cancer or other types of cancer, seem remote and counterintuitive. Yet overdetection is a welldocumented phenomenon that is both biologically plausible and epidemiologically demonstrable (1-5). In population cancer screening, overdetection generally refers to the detection of cancer that, in the absence of screening, would not have been diagnosed nor caused harm in the affected person's lifetime, and would not have become symptomatic or clinically apparent $(4,6)$. Routine screening of asymptomatic individuals has the potential to identify such 'overdetected' disease, leading to the harms of unnecessary treatment (referred to as overtreatment) $(3,4)$. Mechanistically, population mammography screening confers the benefit of breast cancer mortality reduction by finding and hence treating disease at an early stage of growth and development. Therefore, it is not surprising that some of the early-detected disease revealed through screening may not have become biologically manifest, for example if the disease is inherently an indolent subtype, or if the individual's remaining lifespan is shorter than the time required for the disease to biologically progress to clinical presentation $(3,4)$. The latter explanation for cancer overdetection is particularly relevant in older individuals, who are the focus of a recent study that explored older women's perceptions of overdetection of breast cancer (7). Before elaborating on how older women perceive overdetection from breast cancer screening, we first consider the complex issues relating to overdetection in a broader context.

Although the possibility of overdiagnosis from screening programs has been raised as far back as the 1960's (8), overdetection of breast cancer attributed to population mammography screening has been an ongoing debate amongst stakeholders in health practice, and more generally in society, for nearly two decades $(4,9)$. It is noteworthy that overdetection of cancer from population screening is not limited to breast screening - it exists for several other cancers such as prostate and lung cancer $(2,9)$. In a further example, in a scenario where screening of asymptomatic individuals is not routinely recommended, overuse of imaging has witnessed a substantial increase in the incidence of thyroid cancer (specifically low-risk thyroid cancer) in many countries (10), highlighting the widespread manifestation of cancer overdetection in contemporary health systems.

Whilst population screening is a major contributor of cancer overdetection, there are other perhaps less appreciated causes adding to the burden of overdetection and overtreatment, across cancer and numerous other conditions. Shifting thresholds and definitions for ruling in/ out conditions and abnormalities that widen the boundaries for disease labelling increase overdiagnosis (11). Examples are altering the threshold for treatment of conditions (such as hypertension) or diversifying criteria for diagnosis of disease (for example, attention deficit disorder) (11).

\section{Quantifying overdetection}

One of the most challenging aspects of overdetection relates to quantifying its magnitude, and the lack of consensus on the most appropriate methods to estimate its frequency $(1,2,4,5,12)$. Focusing on breast cancer as the exemplar, variable study designs yield an extremely broad 
range of estimates of breast cancer overdetection from $0.3 \%$ to $76.0 \%$ (2). Some of the variability may be due to differences in study-specific definitions of overdetection, however, substantial variability in the methods used to estimate the 'excess number of cancers' from screening drive the divergent estimates of breast cancer overdetection, with many studies suffering from biases or incorporating assumptions that could over- or under-estimate the true extent of overdetection $(2,12,13)$. At present, polarised views on the magnitude of breast cancer overdetection from mammography screening have reached a 'stalemate', and it may be more valuable to focus future research on defining strategies that help mitigate the consequences of overdetection, specifically identifying and agreeing on ways to reduce over-treatment. Uncertainty around the frequency of overdetection attributable to screening is not unique to breast cancer, there are parallels in overdetection estimates from screening for other cancers, reflecting similar methodological issues as outlined for breast cancer, for example the range of estimates of overdetection of prostate cancer is similarly very broad (1.8\% to $88.1 \%$ ) (2).

An alternate approach to framing the amount of overdetection is to estimate the absolute number of overdetected cases alongside the number of individuals who receive the main benefit, for example the number of $\mathrm{BC}$ deaths averted in the context of breast screening. Mandelblatt and colleagues (14) used simulation models to estimate the cumulative outcomes of breast screening, and reported the median value across models for each outcome per 1,000 women screened versus no screening. This work estimated that for biennial mammography screening from age 50 to 74 years, 7 (range, 4-9) BC deaths are averted and 19 (range, 11-34) cases are overdetected (14). Across various scenarios for screening frequency and start ages, modelling consistently showed that for each BC death averted by screening around 2.5 cases are overdetected (14). Expressing the amount of overdetection relative to the amount of benefit using absolute numbers may help women understand the 'trade-off' between these key outcomes of breast cancer screening and could assist research into how women understand or perceive both the benefits and harms of cancer screening.

\section{Women's perceptions of overdetection of breast cancer}

Recent research from Pappadis and colleagues (7), conducted in the USA, has explored the perspectives of women aged 70 years and older (without a history of breast cancer) regarding overdetection of breast cancer. The researchers conducted semi-structured interviews of
59 older women who were recruited using purposive sampling based on race/ethnicity, age and educational level. In the interview, women were presented with two hypothetical scenarios illustrating the benefits and harms of screening including the harm of overdetection (based on Hersch et al., 2015) (15). This study found that few women had heard of overdetection, and even after receiving information explaining overdiagnosis still half did not understand the concept. Many women were sceptical of overdetection and feared it was being used as a way to ration breast screening (7). An overwhelming majority of women (86\%) said that the information about overdetection did not change their mind about screening (7). Women who understood the concept of overdetection were more likely to report that they were considering stopping screening than women who lacked understanding of the concept. Women's views did not differ by race/ethnicity, education, age or screening preferences (7). These findings on the perspectives of older women regarding overdetection are very similar to those from studies conducted in younger women, summarized in Table 1 .

\section{Knowledge and understanding}

Surveys in Australia (20), the United Kingdom $(21,22)$ and the USA $(23,24)$ found that awareness of overdetection is generally low-between 9 and $50 \%$ of respondents in these studies reported that they had heard about overdetection or overdiagnosis. Qualitative studies in the context of breast cancer screening report even lower levels of awareness and understanding of overdetection (Table 1). Overdetection clearly is an unfamiliar concept for many women, however providing information about overdetection has been shown to increase women's understanding, especially in younger women (18) and when more detailed information about overdetection is provided (15). This suggests that providing brief information about overdetection (such as presented in the study by Pappadis) might not be sufficient to effectively increase understanding about overdetection and support informed choice (15-17). Importantly, most women across the different studies report they value receiving information about overdetection and believe other women should be informed (7,15-19).

\section{Attitudes and intention to screen}

For decades, women have been surrounded by public health messages that emphasize the benefits and somewhat ignore the harms of breast cancer screening. This makes the concept of overdetection unfamiliar, counterintuitive, and difficult to understand (25). Pappadis (7) and several other studies 
Table 1 Women's perceptions and understanding of overdetection (OD) of breast cancer (BC) ${ }^{\dagger}$

\begin{tabular}{|c|c|c|c|c|c|}
\hline $\begin{array}{l}\text { Study author; } \\
\text { country }\end{array}$ & $\begin{array}{l}\text { Study design, methods and } \\
\text { population }\end{array}$ & $\begin{array}{l}\text { Women's } \\
\text { awareness, } \\
\text { knowledge }\end{array}$ & $\begin{array}{l}\text { Women's perceptions, } \\
\text { emotions and } \\
\text { attitudes }\end{array}$ & $\begin{array}{l}\text { Screening } \\
\text { intentions and } \\
\text { behaviour }\end{array}$ & Individual differences \\
\hline $\begin{array}{l}\text { Pappadis et al. } \\
2018 \text { (7); USA }\end{array}$ & $\begin{array}{l}\text { Methods: semi-structured } \\
\text { interviews with women } \\
\text { aged } 70 \text { and older }(n=59) \\
\text { with purposive sampling } \\
\text { based on ethnicity, age and } \\
\text { educational level }\end{array}$ & $\begin{array}{l}\text { Limited/ } \\
\text { moderate } \\
\text { understanding } \\
\text { of OD after } \\
\text { information } \\
\text { presented }\end{array}$ & $\begin{array}{l}\text { Uncertainty/distrust of } \\
\text { information, "how can } \\
\text { they know" }\end{array}$ & $\begin{array}{l}\text { Women who did } \\
\text { not understand } \\
\text { OD more likely to } \\
\text { intend to screen }\end{array}$ & $\begin{array}{l}\text { No all women wanted } \\
\text { to know about potential } \\
\text { presence of cancer in } \\
\text { absence of symptoms, } \\
\text { women who preferred not to } \\
\text { know understood OD better }\end{array}$ \\
\hline \multirow[t]{2}{*}{$\begin{array}{l}\text { Hersch et al. } \\
2013(16) ; \\
\text { Australia }\end{array}$} & $\begin{array}{l}\text { Design: qualitative study of } \\
\text { women's responses to OD } \\
\text { information and its influence } \\
\text { on attitudes and screening } \\
\text { intentions }\end{array}$ & $\begin{array}{l}\text { Prior awareness } \\
\text { of OD was } \\
\text { minimal }\end{array}$ & $\begin{array}{l}\text { Concept of OD } \\
\text { challenges existing } \\
\text { beliefs }\end{array}$ & $\begin{array}{l}50 \% \text { OD estimate } \\
\text { made some think } \\
\text { more carefully } \\
\text { about screening }\end{array}$ & $\begin{array}{l}\text { Information preferences } \\
\text { varied: many considered } \\
\text { OD important to take into } \\
\text { account in making an } \\
\text { informed choice, others } \\
\text { wanted to be encouraged to } \\
\text { screen }\end{array}$ \\
\hline & & & & $\begin{array}{l}\text { Many preferred } \\
\text { full, balanced } \\
\text { information }\end{array}$ & \\
\hline
\end{tabular}

Table 1 (continued) 
Table 1 (continued)

\begin{tabular}{|c|c|c|c|c|c|}
\hline $\begin{array}{l}\text { Study author; } \\
\text { country }\end{array}$ & $\begin{array}{l}\text { Study design, methods and } \\
\text { population }\end{array}$ & $\begin{array}{l}\text { Women's } \\
\text { awareness, } \\
\text { knowledge }\end{array}$ & $\begin{array}{l}\text { Women's perceptions, } \\
\text { emotions and } \\
\text { attitudes }\end{array}$ & $\begin{array}{l}\text { Screening } \\
\text { intentions and } \\
\text { behaviour }\end{array}$ & Individual differences \\
\hline \multirow{3}{*}{$\begin{array}{l}\text { Waller et al. } \\
2013 \text { (17); UK }\end{array}$} & $\begin{array}{l}\text { Methods: focus groups with } \\
\text { women aged } 50-71 \text { years } \\
(n=40) \text { of varying screening } \\
\text { history }\end{array}$ & $\begin{array}{l}\text { Others } \\
\text { demonstrated } \\
\text { good } \\
\text { understanding of } \\
\text { OD }\end{array}$ & $\begin{array}{l}\text { Some suspicious OD } \\
\text { is used to justify a } \\
\text { cost-cutting exercise }\end{array}$ & & \\
\hline & & & OD small price to pay & & \\
\hline & & & $\begin{array}{l}\text { OD information } \\
\text { generally considered } \\
\text { important }\end{array}$ & & \\
\hline \multirow{2}{*}{$\begin{array}{l}\text { Hersch et al., } \\
2015 \text { (15); } \\
\text { Australia }\end{array}$} & $\begin{array}{l}\text { Methods: community- } \\
\text { based, parallel-group, RCT } \\
\text { in a cohort of women aged } \\
48-50 \text { years ( } n=879 \text { ) who } \\
\text { had not had mammography } \\
\text { in the past } 2 \text { years }\end{array}$ & $\begin{array}{l}\text { Made an } \\
\text { informed } \\
\text { choice (defined } \\
\text { as adequate } \\
\text { knowledge } \\
\text { and consistent } \\
\text { attitudes and } \\
\text { intentions) }\end{array}$ & $\begin{array}{l}\text { Belief that women } \\
\text { should be given } \\
\text { balanced information, } \\
\text { inclusive of OD }\end{array}$ & & \\
\hline & $\begin{array}{l}\text { Information about } \\
\text { overdetection: explanatory } \\
\text { and quantitative information } \\
\text { in a decision aid. Estimate } \\
\text { based on UK Independent } \\
\text { Review (1 BC death averted } \\
\text { to } 3 \text { OD cases) }\end{array}$ & $\begin{array}{l}\text { Had better } \\
\text { knowledge }\end{array}$ & & & \\
\hline
\end{tabular}

Table 1 (continued) 
Table 1 (continued)

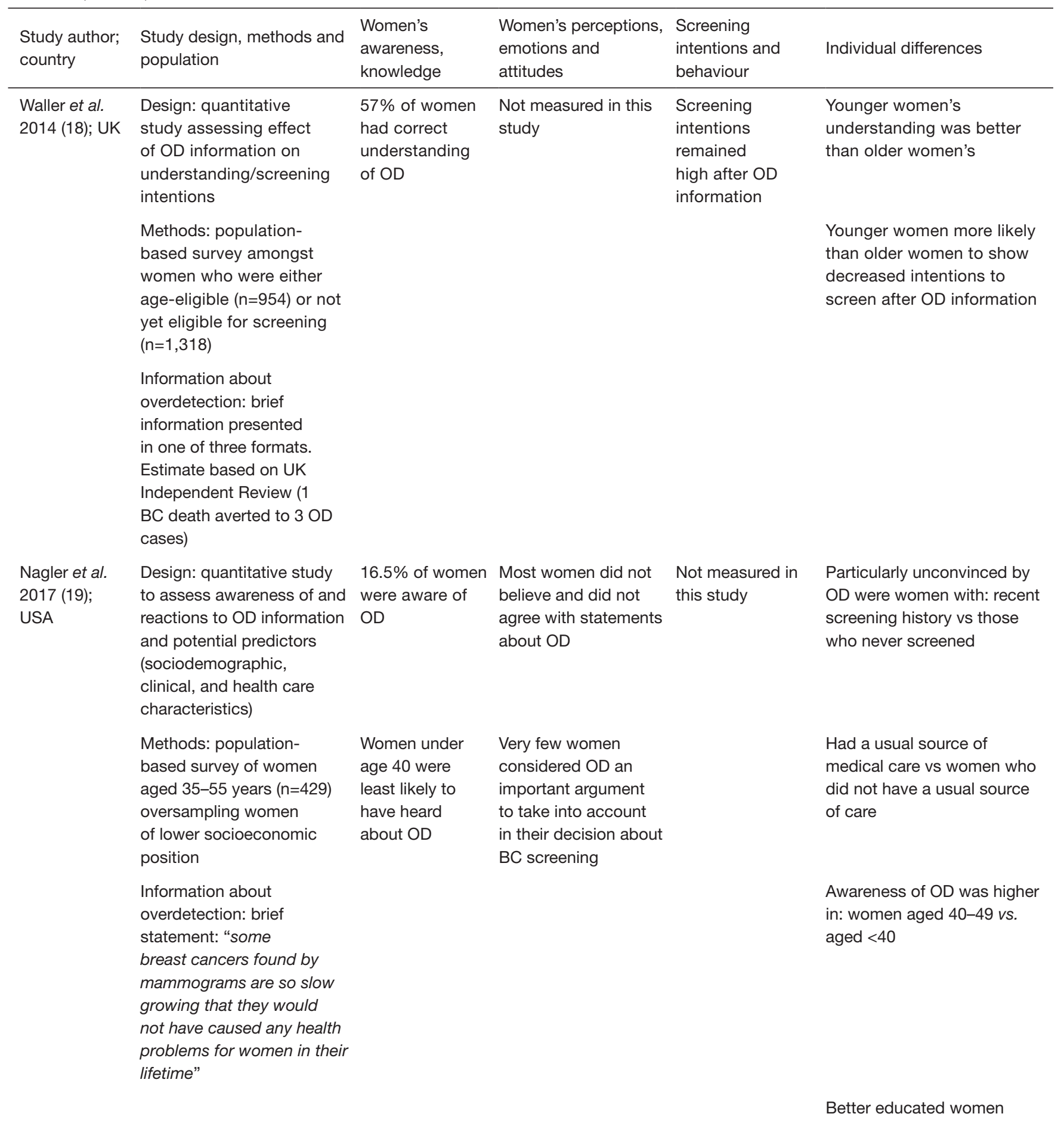

\footnotetext{
${ }^{\dagger}$, studies summarised in the above table did not include women with a personal history of breast cancer.
} 
have found that women are often sceptical of the concept of overdetection and distrust the information provided, suspecting that overdiagnosis is being used as a justification to reduce spending on screening, and questioning how scientists and doctors know that overdetection exists (7,16-19). This can result in emotionally charged and sometimes hostile responses to the concept of overdetection and the idea that breast cancer screening can potentially cause harm (17). It is therefore not surprising that negative responses to information about overdetection seem particularly common in older women and those with a strong screening history $(16,18,19)$ which might also partly explain the findings of Pappadis and colleagues (7).

These results are consistent with an overwhelming enthusiasm for breast cancer screening found across studies, and the limited effect that providing overdetection information has on screening intentions $(7,15-19)$. However, women who are provided with information about overdetection are less likely to say they will start or continue screening compared to women not receiving this information (Table 1). The Pappadis study suggests that this is particularly the case for women who have better understanding of the concept of overdetection (7). Importantly, younger women and those who have never been screened before are more open to the idea of overdetection $(16,18,19)$, perhaps because they are not yet as invested in breast screening as older women. Regardless, across studies, including the study from Pappadis, a majority of women recognise that screening decisions are personal decisions and that women should receive balanced information about potential harms as well as benefits, with a minority preferring to be encouraged to screen $(16,17)$. Studies suggest that for some women information about overdetection might not influence their decision to screen, rather it might change their treatment decision-making once diagnosed, potentially opting for alternative approaches such as watchful waiting $(16,17)$.

\section{Women's concerns about overdetection information.}

Women have reported concerns about the potential for overdetection information to upset women who had previously accepted invitations to screening or those already diagnosed with breast cancer, and that it might dissuade others from screening (although it would not dissuade them personally) $(16,17)$. Fears have also been raised that changing the conventional pro-screening message to include more balanced information on screening outcomes could unleash widespread public confusion and distrust in the health system (16). On the other hand, women in several studies expressed concerns about the harms of potentially unnecessary treatment for screen-detected breast cancer and the importance of making information about overdetection widely available $(16,17)$. Others have commented that awareness of overdetection might help newly diagnosed women to feel less afraid and more hopeful about their prognosis $(16,17)$.

\section{Conclusions}

Understanding and quantifying overdetection from breast screening is a complex issue (with parallels in screening for other cancers), highlighted in the ongoing nonconsensus about breast cancer overdetection amongst screening experts and stakeholders. It is not surprising then that communicating information to women about overdetection from breast screening is challenging. The findings from Pappadis and colleagues (7) emphasise the need for providing good-quality information on screening outcomes and to communicate this information effectively, so that women can understand the concept and are better positioned to make well-informed decisions. Future research is needed to determine how information about overdetection in breast cancer screening can be communicated in a way that is believable and not so counterintuitive, and how we can tailor such information to meet the needs of women from different ages and screening histories, varying levels of health literacy and in line with their information preferences.

\section{Acknowledgments}

Funding: This work was supported by a National Breast Cancer Foundation (NBCF Australia), Breast Cancer Research Leadership Fellowship (to N Houssami).

\section{Footnote}

Provenance and Peer Review: This article was commissioned by the editorial office, Translational Cancer Research. The article did not undergo external peer review.

Conflicts of Interest: Both authors have completed the ICMJE uniform disclosure form (available at http://dx.doi. org/10.21037/tcr.2018.09.08). The authors have no conflicts of interest to declare.

Ethical Statement: The authovrs are accountable for all aspects of the work in ensuring that questions related to the accuracy or integrity of any part of the work are appropriately investigated and resolved. 
Open Access Statement: This is an Open Access article distributed in accordance with the Creative Commons Attribution-NonCommercial-NoDerivs 4.0 International License (CC BY-NC-ND 4.0), which permits the noncommercial replication and distribution of the article with the strict proviso that no changes or edits are made and the original work is properly cited (including links to both the formal publication through the relevant DOI and the license). See: https://creativecommons.org/licenses/by-nc-nd/4.0/.

\section{References}

1. Barratt A. Overdiagnosis in mammography screening: a 45 year journey from shadowy idea to acknowledged reality. BMJ 2015;350:h867.

2. Carter JL, Coletti RJ, Harris RP. Quantifying and monitoring overdiagnosis in cancer screening: a systematic review of methods. BMJ 2015;350:g7773.

3. Esserman LJ, Thompson IM, Reid B. Overdiagnosis and overtreatment in cancer: An opportunity for improvement. JAMA 2013;310:797-8.

4. Houssami N. Overdiagnosis of breast cancer in population screening: does it make breast screening worthless? Cancer Biol Med 2017;14:1-8.

5. Hubbard RA. US counties with higher rates of breast cancer screening have higher rates of incidence with no concomitant decrease in breast cancer mortality suggesting overdiagnosis. Evid Based Med 2015;20:201.

6. Lauby-Secretan B, Scoccianti C, Loomis D, et al. BreastCancer Screening - Viewpoint of the IARC Working Group. New Engl J Med 2015;372:2353-8.

7. Pappadis MR, Volk RJ, Krishnan S, et al. Perceptions of overdetection of breast cancer among women 70 years of age and older in the USA: a mixed-methods analysis. BMJ Open 2018;8:e022138.

8. Feinleib M, Zelen M. Some Pitfalls in the Evaluation of Screening Programs. Arch Environ Health 1969;19:412-5.

9. Carter SM, Rogers W, Heath I, et al. The challenge of overdiagnosis begins with its definition. BMJ 2015;350:h869.

10. Brito JP, Morris JC, Montori VM. Thyroid cancer: zealous imaging has increased detection and treatment of low risk tumours. BMJ 2013;347:f4706.

11. Moynihan RN, Cooke GPE, Doust JA, et al. Expanding Disease Definitions in Guidelines and Expert Panel Ties to Industry: A Cross-sectional Study of Common Conditions in the United States. PLoS Med 2013;10:e1001500.

12. Etzioni R, Gulati R, Mallinger L, et al. Influence of Study Features and Methods on Overdiagnosis Estimates in Breast and Prostate Cancer Screening. Ann Intern Med 2013;158:831-8.

13. Biesheuvel C, Barratt A, Howard K, et al. Effects of study methods and biases on estimates of invasive breast cancer overdetection with mammography screening: a systematic review. Lancet Oncol 2007;8:1129-38.

14. Mandelblatt JS, Stout NK, Schechter CB, et al. Collaborative Modeling of the Benefits and Harms Associated With Different U.S. Breast Cancer Screening Strategies. Ann Intern Med 2016;164:215-25.

15. Hersch J, Barratt A, Jansen J, et al. Use of a decision aid including information on overdetection to support informed choice about breast cancer screening: a randomised controlled trial. Lancet 2015;385:1642-52.

16. Hersch J, Jansen J, Barratt A, et al. Women's views on overdiagnosis in breast cancer screening: a qualitative study. BMJ 2013;346:f158.

17. Waller J, Douglas E, Whitaker KL, et al. Women's responses to information about overdiagnosis in the UK breast cancer screening programme: a qualitative study. BMJ Open 2013;3:e002703.

18. Waller J, Whitaker KL, Winstanley K, et al. A survey study of women's responses to information about overdiagnosis in breast cancer screening in Britain. Br J Cancer 2014;111:1831-5.

19. Nagler RH, Franklin Fowler E, Gollust SE. Women's Awareness of and Responses to Messages About Breast Cancer Overdiagnosis and Overtreatment: Results From a 2016 National Survey. Med Care 2017;55:879-85.

20. Moynihan R, Nickel B, Hersch J, et al. Public opinions about overdiagnosis: a national community survey. PLoS One 2015;10:e0125165.

21. Ghanouni A, Meisel SF, Renzi C, et al. Survey of public definitions of the term 'overdiagnosis' in the UK. BMJ Open 2016;6:e010723.

22. Van den Bruel A, Jones C, Yang Y, et al. People's willingness to accept overdetection in cancer screening: population survey. BMJ 2015;350:h980.

23. Yu J, Nagler RH, Fowler EF, et al. Women's Awareness and Perceived Importance of the Harms and Benefits of Mammography Screening: Results From a 2016 National Survey. JAMA Intern Med 2017;177:1381-2.

24. Schwartz LM, Woloshin S, Fowler, et al. Enthusiasm for cancer screening in the united states. JAMA 2004;291:71-8.

25. McCaffery KJ, Jansen J, Scherer LD, et al. Walking the tightrope: communicating overdiagnosis in modern healthcare. BMJ 2016;352:i348.

Cite this article as: Jansen J, Houssami N. Perceptions and misperceptions of overdetection of breast cancer. Transl Cancer Res 2018;7(6):1347-1353. doi: 10.21037/tcr.2018.09.08 